\title{
Proteína hidrolisada de frango em dietas para alevinos de tilápia
}

\author{
Poultry protein hydrolysates in diets for tilapia fingerlings \\ Proteína de pollo hidrolizada en dietas para alevines tilapia
}

Recebido: 1410/2021 | Revisado: 1910/2021 | Aceito: 26/10/2021 | Publicado: 29/10/2021

\author{
Joana D'Arc Maurício Rocha \\ ORCID: https://orcid.org/0000-0002-7131-2349 \\ Universidade do Estado do Amapá, Brasil \\ E-mail: joanadmrocha@hotmail.com \\ Janaína Fernanda Rossetto \\ ORCID: https://orcid.org/0000-0003-2438-2122 \\ Universidade Estadual do Oeste do Paraná, Brasil \\ E-mail: janafer_rossetto@hotmail.com \\ Thibério Carvalho da Silva \\ ORCID: https://orcid.org/0000-0002-9725-0887 \\ Universidade do Estado do Amapá, Brasil \\ E-mail: thiberiocs@hotmail.com \\ Aldi Feiden \\ ORCID: https://orcid.org/0000-0002-6823-9291 \\ Universidade Estadual do Oeste do Paraná, Brasil \\ E-mail: aldifeiden@gmail.com \\ Fábio Bittencourt \\ ORCID: https://orcid.org/0000-0001-5894-7158 \\ Universidade Estadual do Oeste do Paraná, Brasil \\ E-mail: bitanca@hotmail.com \\ Wilson Rogério Boscolo \\ ORCID: https://orcid.org/0000-0002-1808-0518 \\ Universidade Estadual do Oeste do Paraná, Brasil \\ E-mail:wilsonboscolo@hotmail.com \\ Altevir Signor \\ ORCID: https://orcid.org/0000-0002-4659-6466 \\ Universidade Estadual do Oeste do Paraná, Brasil \\ E-mail: altevir.signor@gmail.com
}

\begin{abstract}
Resumo
O presente estudo teve por objetivo avaliar parâmetros do desempenho produtivo de alevinos de tilápia do Nilo alimentados com dietas contendo níveis de proteína hidrolisada de frango (PHF). Foram utilizados 420 animais com peso médio de 1,8 $\pm 0,7 \mathrm{~g}$ distribuídos em um delineamento inteiramente casualizado com sete tratamentos e quatro repetições. Os animais foram alocados em 28 tanques de $70 \mathrm{~L}$ de volume útil com aeração artificial por meio de soprador de ar. Foram elaboradas sete dietas, sendo uma ração controle e outras seis rações com níveis crescentes de inclusão da proteína hidrolisada de frango $(0 ; 1 ; 2 ; 3 ; 4 ; 5$ e $6 \%)$. Os animais foram alimentados seis vezes ao dia por 30 dias e, ao fim do período experimental foram tomadas as medidas de peso e comprimento total para posterior cálculo dos parâmetros produtivos, além de coleta de material biológico para histologia. Os dados foram submetidos a análise de variância (ANOVA) e análise de regressão polinomial a 5\% de probabilidade. Foram observados efeitos quadráticos $(\mathrm{p}<0,05)$ para peso final $(3,08 \%)$, ganho em peso $(3,00 \%)$, taxa de crescimento específica $(3,06 \%)$, conversão alimentar aparente $(3,63 \%)$ e taxa de eficiência proteica $(2,91 \%)$. As diferentes dietas não influenciaram $(\mathrm{p}>0,05)$ o comprimento total, a sobrevivência e as morfometrias do músculo, fígado e intestino dos alevinos. A inclusão de PHF não prejudicou a performance produtiva dos alevinos de tilápia do Nilo em níveis de até $6 \%$ deste produto nas dietas. Portanto, recomenda-se a utilização de 3\% de PHF para melhor ganho em peso dos animais.
\end{abstract}

Palavras-chave: Hidrolisado proteico; Nutrição; Hidrólise; Ingrediente; Coproduto.

\begin{abstract}
The present study aimed to evaluate parameters of productive performance of Nile tilapia fingerlings fed with diets containing levels of hydrolyzed chicken protein (PHF). A total of 420 animals with an average weight of $1.8 \pm 0.7 \mathrm{~g}$ were used, distributed in a completely randomized design with seven treatments and four replications. The animals were placed in 28 tanks of $70 \mathrm{~L}$ of useful volume with artificial aeration using an air blower. Seven diets were prepared, one control ration and another six rations with increasing levels of inclusion of hydrolyzed chicken protein $(0,1,2,3,4,5$ and $6 \%)$. The animals were fed six times a day for 30 days and, at the end of the experimental period, weight and total length measurements were taken for later calculation of production parameters, in addition to the collection of biological material for histology. Data were subjected to analysis of variance (ANOVA) and polynomial
\end{abstract}


regression analysis at $5 \%$ probability. Quadratic effects $(\mathrm{p}<0.05)$ were observed for final weight $(3.08 \%)$, weight gain $(3.00 \%)$, specific growth rate $(3.06 \%)$, apparent feed conversion $(3.63 \%)$ and protein efficiency rate $(2.91 \%)$. The different diets did not influence $(p>0.05)$ the total length, survival and muscle, liver and intestine morphometry of fingerlings. The inclusion of PHF did not affect the productive performance of Nile tilapia fingerlings at levels of up to $6 \%$ of this product in the diets. Therefore, it is recommended to use $3 \%$ of PHF for better weight gain of animals.

Keywords: Protein hydrolyzate; Nutrition; Hydrolysis; Ingrediente; Co-product.

\section{Resumen}

El presente estudio tuvo como objetivo evaluar parámetros del comportamiento productivo de alevines de tilapia del Nilo alimentados con dietas que contienen niveles de proteína de pollo hidrolizada (PHF). Se utilizaron un total de 420 animales con un peso promedio de $1.8 \pm 0.7 \mathrm{~g}$, distribuidos en un diseño completamente al azar con siete tratamientos y cuatro repeticiones. Los animales se colocaron en 28 tanques de $70 \mathrm{~L}$ de volumen útil con aireación artificial utilizando un soplador de aire. Se prepararon siete dietas, una ración control y otras seis raciones con niveles crecientes de inclusión de proteína de pollo hidrolizada $(0,1,2,3,4,5$ y 6\%). Los animales fueron alimentados seis veces al día durante 30 días y, al final del período experimental, se tomaron medidas de peso y longitud total para el cálculo posterior de los parámetros de producción, además de la recolección de material biológico para histología. Los datos se sometieron a análisis de varianza (ANOVA) y análisis de regresión polinomial al 5\% de probabilidad. Se observaron efectos cuadráticos $(\mathrm{p}<0.05)$ para el peso final $(3.08 \%)$, ganancia de peso $(3.00 \%)$, tasa de crecimiento específico $(3.06 \%)$, conversión aparente de alimento (3.63\%) y tasa de eficiencia proteica (2.91\%). Las diferentes dietas no influyeron ( $\mathrm{p}>0.05$ ) en la longitud total, supervivencia y morfometría de músculo, hígado e intestino de los alevines. La inclusión de PHF no afectó el desempeño productivo de los alevines de tilapia del Nilo a niveles de hasta el $6 \%$ de este producto en las dietas. Por tanto, se recomienda utilizar un $3 \%$ de PHF para una mejor ganancia de peso de los animales.

Palabras clave: Hidrolizado de proteínas; Nutrición; Hidrólisis; Ingrediente; Coproducto.

\section{Introdução}

A criação de tilápia vêm sendo uma das mais importantes atividades agrárias de produção de carne, além de ser responsável pela consolidação da cadeia produtiva aquícola no país, constituindo uma importante fonte de emprego e renda aos envolvidos (Alves et al. 2019).

De acordo com Brito et al. (2017), para o aumento da produtividade na tilapicultura diversas etapas da atividade demandam esforços técnico-científicos como no melhoramento genético dos animais, automação na atividade, facilidade e sucesso na obtenção de formas jovens, tecnologias para estocagem dos animais, manejo, sanidade, nutrição, processamento e conservação. Considerando que a nutrição é um dos principais entraves nestes sistemas produtivos, por representar o maior aporte de investimento da atividade, torna-se fundamental que estratégias que contribuam para amenizar tais aportes financeiros bem como melhorar funções nutricionais sejam desenvolvidas (Brito et al, 2017).

A necessidade de novas possibilidades nutricionais, reforçadas pela forte concorrência por fontes proteicas usuais como farinha de peixe em outros segmentos industriais, demandam esforços científicos e inovadores para garantir o pleno desenvolvimento desta cadeia produtiva. Dessa forma, a prospecção de matérias-primas aliado ao uso de biotecnologias que otimizem características nutricionais são consideradas possibilidades com potencial para atender a este segmento (Alves et al. 2019; Dieterich et al. 2014; Sary et al. 2017).

$\mathrm{O}$ processo de hidrólise enzimática vem sendo aplicado às mais diversas matérias-primas com intuito de melhorar características nutricionais e funcionais, pois a partir da quebra das estruturas proteicas, este processo proporciona a geração de fragmentos de menor tamanho (peptídeos e aminoácidos livres), além de grupos funcionais com bioatividades benéficas ao organismo (Kristinsson \& Rasco, 2000; Dieterich et al. 2014; Sary et al. 2017).

Coprodutos agroindustriais são alternativas nutricionais e econômicas para fornecer o aporte biológico nas rações para organismos aquáticos, visto que apresentam grande volume de produção, poucas possibilidades de aproveitamento e principalmente, elevada qualidade biológica (Mullen et al, 2017).

O emprego da biotecnologia de hidrólise enzimática em coprodutos agroindústrias proporciona um produto com melhoria nutricional e funcional, podendo contribuir com aspectos da saúde dos animais que o consomem. Assim, o presente 
estudo teve por objetivo avaliar a proteína hidrolisada de frango (PHF) em dietas para alevinos de tilápia do Nilo através de aspectos do desempenho produtivo e alterações no músculo, intestino e fígado destes animais.

\section{Metodologia}

O experimento foi realizado no Laboratório de Aquicultura do Curso de Engenharia de Pesca da Universidade Estadual do Oeste do Paraná - Unioeste - Campus de Toledo. A fabricação da ração e as análises histológicas foram realizadas nos Laboratórios do Grupo de Estudos de Manejo na Aquilcultura - GEMAq.

Este estudo foi aprovado pelo Comitê de Ética no Uso de Animais da UNIOESTE sob o protocolo $n^{\circ} 52 / 17$. A proteína hidrolisada de frango utilizada neste estudo foi cedida pela empresa BRF Ingredients Ltda.

Os alevinos de tilápia do Nilo foram distribuídos em delineamento inteiramente ao acaso com sete tratamentos e quatro repetições. Foram utilizados 15 alevinos de tamanho comercial com cerca de $1,8 \mathrm{~g}$ distribuídos aleatoriamente em 28 tanques com volume de $70 \mathrm{~L}$ para cada repetição. $\mathrm{O}$ experimento foi conduzido por 30 dias.

Foram elaboradas uma ração controle contendo farinha de peixe ( $0 \%$ PHF) e outras seis rações com níveis crescentes de inclusão da proteína hidrolisada de frango (1, 2, 3, 4, 5 e 6\%) (Tabela 1). As rações foram formuladas de forma a serem isoenergéticas, isoprotéicas e isoaminoácidicas e com base em exigências propostas por NRC (2011).

Os ingredientes utilizados foram triturados em moinho do tipo martelo em peneira de $0,3 \mathrm{~mm}$, pesados, misturados, extrusados em extrusora ExMicro® em matriz de $1 \mathrm{~mm}$ e secos em estufa de ar forçado a $55^{\circ} \mathrm{C}$ por $24 \mathrm{~h}$ para retirada da umidade adquirida para processamento das rações.

O manejo alimentar utilizado neste estudo foi através de seis alimentações diárias, sendo às $8,10,12,14,16$ e 18h, quando as rações foram ofertadas até a saciedade aparente dos animais. Ao final de cada dia, os tanques foram sifonados para retirada de resíduos de excretas dos animais. 
Tabela 1. Formulação e composição de nutrientes das rações experimentais com inclusão de níveis de proteína hidrolisada de frango (PHF) para alevinos de tilápia do Nilo O. niloticus.

\begin{tabular}{|c|c|c|c|c|c|c|c|}
\hline \multirow{2}{*}{ Ingredientes } & \multicolumn{7}{|c|}{ Dietas contendo PHF (\%) } \\
\hline & $\mathbf{0}$ & 1 & 2 & 3 & 4 & 5 & 6 \\
\hline Farelo de soja & 30,00 & 30,00 & 30,00 & 30,00 & 30,00 & 30,00 & 30,00 \\
\hline Fubá de milho & 23,23 & 23,31 & 23,39 & 23,47 & 23,55 & 23,63 & 23,72 \\
\hline Farinha de penas & 10,00 & 10,00 & 10,00 & 10,00 & 10,00 & 10,00 & 10,00 \\
\hline Farinha de vísceras de aves & 10,00 & 10,00 & 10,00 & 10,00 & 10,00 & 10,00 & 10,00 \\
\hline Quirera de arroz & 8,00 & 8,00 & 8,00 & 8,00 & 8,00 & 8,00 & 8,00 \\
\hline Farinha de peixe & 6,00 & 5,00 & 4,00 & 3,00 & 2,00 & 1,00 & 0,00 \\
\hline PHF & $\mathbf{0 , 0 0}$ & 1,00 & 2,00 & 3,00 & 4,00 & 5,00 & 6,00 \\
\hline Glúten de milho & 3,59 & 3,59 & 3,60 & 3,61 & 3,62 & 3,63 & 3,64 \\
\hline Óleo de soja & 2,00 & 1,94 & 1,87 & 1,81 & 1,75 & 1,69 & 1,62 \\
\hline Concentrado de soja & 1,49 & 1,24 & 0,99 & 0,75 & 0,50 & 0,25 & 0,00 \\
\hline L-Lisina HCL & 1,25 & 1,24 & 1,24 & 1,24 & 1,23 & 1,23 & 1,22 \\
\hline Glúten de trigo & 1,00 & 1,00 & 1,00 & 1,00 & 1,00 & 1,00 & 1,00 \\
\hline L-Treonina & 0,85 & 0,85 & 0,85 & 0,85 & 0,84 & 0,84 & 0,84 \\
\hline Premix peixes $^{1}$ & 0,60 & 0,60 & 0,60 & 0,60 & 0,60 & 0,60 & 0,60 \\
\hline Levedura álcool & 0,50 & 0,50 & 0,50 & 0,50 & 0,50 & 0,50 & 0,50 \\
\hline Dl-Metionina & 0,43 & 0,43 & 0,43 & 0,43 & 0,43 & 0,43 & 0,43 \\
\hline Sal comum & 0,30 & 0,30 & 0,30 & 0,30 & 0,30 & 0,30 & 0,30 \\
\hline Fosfato bicálcico & 0,21 & 0,33 & 0,45 & 0,56 & 0,68 & 0,80 & 0,91 \\
\hline Cloreto de colina & 0,20 & 0,20 & 0,20 & 0,20 & 0,20 & 0,20 & 0,20 \\
\hline Vitamina C & 0,20 & 0,20 & 0,20 & 0,20 & 0,20 & 0,20 & 0,20 \\
\hline Antifúngico & 0,10 & 0,10 & 0,10 & 0,10 & 0,10 & 0,10 & 0,10 \\
\hline L-Triptofano & 0,03 & 0,03 & 0,04 & 0,04 & 0,04 & 0,05 & 0,05 \\
\hline Antioxidante & 0,02 & 0,02 & 0,02 & 0,02 & 0,02 & 0,02 & 0,02 \\
\hline Calcário & 0,00 & 0,11 & 0,22 & 0,32 & 0,43 & 0,54 & 0,65 \\
\hline \multicolumn{8}{|l|}{ Nutrientes calculados $(\%)$} \\
\hline Ácido Linoleico & 2,26 & 2,22 & 2,17 & 2,13 & 2,08 & 2,04 & 1,99 \\
\hline Amido & 25,00 & 24,95 & 24,90 & 24,85 & 24,79 & 24,74 & 25,31 \\
\hline Cálcio & 1,07 & 1,07 & 1,07 & 1,07 & 1,07 & 1,07 & 1,07 \\
\hline Energia Digestível & 3400 & 3400 & 3400 & 3400 & 3400 & 3400 & 3400 \\
\hline Fibra bruta & 2,14 & 2,14 & 2,13 & 2,13 & 2,12 & 2,12 & 2,11 \\
\hline Fósforo total & 0,80 & 0,80 & 0,80 & 0,80 & 0,80 & 0,80 & 0,80 \\
\hline Gordura & 6,04 & 5,95 & 5,86 & 5,77 & 5,68 & 5,59 & 5,50 \\
\hline Lisina & 2,80 & 2,80 & 2,80 & 2,80 & 2,80 & 2,80 & 2,80 \\
\hline Matéria mineral & 5,44 & 5,30 & 5,16 & 5,02 & 4,88 & 4,74 & 4,60 \\
\hline Metionina total & 1,00 & 1,00 & 1,00 & 1,00 & 1,00 & 1,00 & 1,00 \\
\hline Proteína bruta & 40,00 & 40,00 & 40,00 & 40,00 & 40,00 & 40,00 & 40,00 \\
\hline Treonina & 2,38 & 2,38 & 2,38 & 2,38 & 2,38 & 2,38 & 2,38 \\
\hline Triptofano & 0,40 & 0,40 & 0,40 & 0,40 & 0,40 & 0,40 & 0,40 \\
\hline
\end{tabular}

${ }^{1}$ Níveis de garantia por quilograma do produto: vit. A - $500.000 \mathrm{UI}$; vit. D3 - $200.000 \mathrm{UI}$; vit. E - 5.000 mg; vit. K3 $1.000 \mathrm{mg}$; vit. B1 - $1.500 \mathrm{mg}$; vit. B2 - $1.500 \mathrm{mg}$; vit. B6 - $1.500 \mathrm{mg}$; vit. B12 - $4.000 \mathrm{mg}$; ácido fólico - $500 \mathrm{mg}$; pantotenato de cálcio - $4.000 \mathrm{mg}$; vit. C - $15.000 \mathrm{mg}$; biotina - $50 \mathrm{mg}$; inositol - 10.000; nicotinamida - 7.000; colina $40.000 \mathrm{mg}$; cobalto - $10 \mathrm{mg}$; cobre - $500 \mathrm{mg}$; ferro - $5.000 \mathrm{mg}$; iodo - $50 \mathrm{mg}$; manganês - $1.500 \mathrm{mg}$; selênio - $10 \mathrm{mg}$; zinco - $5.000 \mathrm{mg}$.

Fonte: Autores. 
Após período experimental, os peixes foram mantidos em jejum por 24 horas para esvaziamento do trato gastrointestinal e, posteriormente, os animais foram insensibilizados em benzocaína, na dose de $100 \mathrm{mg} / \mathrm{L}^{-1}$ para realização das medidas individuais de peso $(\mathrm{g})$, comprimento total $(\mathrm{cm})$ e contados para avalição da taxa de sobrevivência. Também foi mensurada a quantidade de ração consumida por cada tanque para calcular a conversão alimentar aparente dos peixes de todas as unidades experimentais.

Os parâmetros de desempenho produtivo avaliados foram: o peso final $(\mathrm{g})$, comprimento total final $(\mathrm{cm})$, ganho em peso [peso final $(\mathrm{g})$ - peso inicial $(\mathrm{g})$ ], conversão alimentar aparente [alimento consumido (g)/ganho em peso (g)], taxa de crescimento específico [(ln do peso final $(\mathrm{g})$ - ln do peso inicial (g)/tempo do experimento (dias))*100], taxa de eficiência proteica [ganho em peso/proteína consumida] e a sobrevivência $\left[\left(\mathrm{n}^{\circ} \text { de peixes } / 15\right)^{*} 100\right]$ dos animais submetidos às diferentes dietas.

As alterações fisiológicas nos peixes, foram avaliadas por meio da eutanasia de três animais por tanque com superdosagem de $200 \mathrm{mg} / \mathrm{L}^{-1}$ de benzocaína (Okamura et al. 2010). Com auxílio de bisturi, tesouras e pinças cirúrgicas foram retiradas as amostras padronizadas de músculo, fígado e intestino. Esse material foi fixado em solução Alfac por 24h, posteriormente foi conservado em álcool (70\%). Processamento da amostra seguiu com a realização de desidratação em concentrações crescentes de álcool (70 a 100\%), diafanização em xilol, emblocação em parafina para então realizar os cortes histológicos em micrótomo (Microm, International Gmbh 69190) com $5 \mu$ de espessura. As amostras foram dispostas em lâminas de vidro e submetidas à técnica de coloração HE (hematoxilina e eosina). Cada amostra foi analisada em microscópio óptico (Olympus BX 50) com câmera digital (Olympus PMC 35 B) acoplada para captura de imagens.

Para avaliação do crescimento das fibras musculares, foram tomadas as medidas de maior diâmetro de 200 dessas estruturas por animal e agrupadas em i) menor que $20 \mu \mathrm{m}(<20 \mu \mathrm{m})$, ii) de 20 a $50 \mu \mathrm{m}$ (20 a $50 \mu \mathrm{m})$ e iii) maior que $50 \mu \mathrm{m}$ ( $>50 \mu \mathrm{m}$ ) baseado na metodologia de Valente et al. (1999). A alteração do tecido hepático foi avaliada pelo número total de hepatócitos em uma área de $20000 \mu \mathrm{m}$. Para determinar as alterações no intestino, foram mensurados a altura da vilosidade e espessura do epitélio.

Os dados obtidos foram submetidos a análises de variância (ANOVA) e quando observadas diferenças estatísticas foi realizada análise de regressão linear ou quadrática por meio do programa computacional Statistic 7.1 (Statsoft, 2005).

\section{Resultados e Discussão}

A proteína hidrolisada de frango (PHF) influenciou a performance produtiva dos alevinos de tilápia do Nilo $(\mathrm{p}<0,05)$, exceto para os parâmetros de comprimento total final e taxa de sobrevivência (Tabela 2). 
Tabela 2. Desempenho produtivo de alevinos de tilápia do Nilo alimentados com dietas contendo níveis crescentes de proteína hidrolisada de frango (PHF).PF: peso final médio; CT: comprimento final médio; GP: ganho em peso; TCE: taxa de crescimento específico; CAA: conversão alimentar aparente; TEP: taxa de eficiência proteica; SO: sobrevivência.

\begin{tabular}{|c|c|c|c|c|c|c|c|c|}
\hline \multirow{2}{*}{ Variáveis } & \multicolumn{7}{|c|}{ Níveis de inclusão de PHF (\%) } & \multirow{2}{*}{ Efeito } \\
\hline & $\mathbf{0}$ & 1 & 2 & 3 & 4 & 5 & 6 & \\
\hline PF (g) & $5,11 \pm 0,38$ & $5,92 \pm 0,52$ & $6,26 \pm 0,15$ & $6,21 \pm 0,50$ & $5,71 \pm 0,52$ & $5,61 \pm 0,21$ & $5,55 \pm 0,51$ & Quadrático \\
\hline CT (mm) & $67,56 \pm 1,03$ & $69,92 \pm 1,25$ & $70,20 \pm 0,54$ & $69,36 \pm 3,06$ & $68,18 \pm 1,57$ & $68,94 \pm 1,13$ & $68,94 \pm 2,67$ & NS \\
\hline GP $(\mathbf{g})$ & $3,31 \pm 0,38$ & $4,12 \pm 0,52$ & $4,46 \pm 0,25$ & $4,41 \pm 0,60$ & $3,91 \pm 0,52$ & $3,81 \pm 0,21$ & $3,75 \pm 0,51$ & Quadrático \\
\hline TCE (\%) & $3,31 \pm 0,38$ & $4,12 \pm 0,52$ & $4,46 \pm 0,25$ & $4,41 \pm 0,60$ & $3,91 \pm 0,52$ & $3,81 \pm 0,21$ & $3,75 \pm 0,51$ & Quadrático \\
\hline CAA（g/g) & $1,79 \pm 0,26$ & $1,34 \pm 0,45$ & $1,09 \pm 0,05$ & $1,15 \pm 0,10$ & $1,19 \pm 0,08$ & $1,37 \pm 0,35$ & $1,28 \pm 0,13$ & Quadrático \\
\hline TEP (\%) & $1,06 \pm 0,21$ & $1,32 \pm 0,32$ & $1,49 \pm 0,11$ & $1,41 \pm 0,07$ & $1,34 \pm 0,14$ & $1,44 \pm 0,23$ & $1,25 \pm 0,13$ & Quadrático \\
\hline \multirow[t]{2}{*}{ SO (\%) } & $85 \pm 8,38$ & $85 \pm 13,74$ & $88,88 \pm 3,84$ & $86,66 \pm 12,17$ & $91,66 \pm 6,38$ & $80 \pm 16,32$ & $90 \pm 11,54$ & NS \\
\hline & \multicolumn{6}{|c|}{ Equações } & \multicolumn{2}{|c|}{ valor de $p$} \\
\hline $\mathbf{P F}$ & \multicolumn{6}{|c|}{$y=-0,087 x^{2}+0,5326 x+5,3457 . R^{2}=0,3406 ;$ PHF $=\mathbf{3 , 0 8 \%}$} & \multicolumn{2}{|c|}{0,0022} \\
\hline GP & \multicolumn{6}{|c|}{$y=-0,0866 x^{2}+0,5267 x+3,5092 . R^{2}=0,329 ;$ PHF $=\mathbf{3 , 0 0 \%}$} & \multicolumn{2}{|c|}{0,0022} \\
\hline TCE & \multicolumn{6}{|c|}{$y=-0,051 x^{2}+0,3126 x+3,5903 . R^{2}=0,3366 ;$ PHF $=\mathbf{3 , 0 6 \%}$} & \multicolumn{2}{|c|}{0,0019} \\
\hline CAA & \multicolumn{6}{|c|}{$y=0,0456 x^{2}-0,33 x+1,6617 . R^{2}=0,5916 ; P H F=\mathbf{3 , 6 2 \%}$} & \multicolumn{2}{|c|}{0,0040} \\
\hline TEP & \multicolumn{6}{|c|}{$y=-0,0297 x^{2}+0,1729 x+1,1729 . R^{2}=0,266 ; P H F=\mathbf{2 , 9 1 \%}$} & \multicolumn{2}{|c|}{0,0151} \\
\hline
\end{tabular}

NS: não significativo (p>0,05); PHF: proteína hidrolisada de frango. Fonte: Autores.

A inclusão da PHF nas dietas demonstrou melhor expressão dos parâmetros de crescimento quando comparada com o tratamento controle, que utilizou farinha de peixe em substituição total ao ingrediente testado, ou seja, na dieta controle não houve a inclusão de PHF. A análise de regressão polinomial revelou efeito quadrático para peso final, ganho em peso, taxa de crescimento especifico, conversão alimentar aparente e taxa de eficiência proteica e nenhum efeito foi observado para o comprimento total final e sobrevivência.

Estudos com proteínas hidrolisadas na alimentação de organismos aquáticos vêm demonstrando melhoras nos aspectos produtivos desses animais (Hevroy et al., 2005; Zheng et al., 2012; Arredondo-Figueroa et al., 2013; Dieterich et al. 2014; Sary et al. 2017; Silva et al., 2017).

Fracalossi et al. (2012) ressaltam que os parâmetros relacionados ao crescimento (peso final, comprimento final, ganho em peso, taxa de crescimento específico) são os aspectos mais importantes para expressar a resposta dos peixes às dietas e ingredientes experimentais, uma vez que é a medida com maior aplicabilidade na produção, onde se espera por maior produtividade e consequente lucratividade pela maior biomassa.

As derivações das equações indicaram inclusão ótima de 3,08\% de PHF para o peso final, 3,00\% para ganho em peso, $3,06 \%$ para a taxa de crescimento específico, 3,62\% para conversão alimentar aparente e 2,91\% para taxa de eficiência proteica (Figura 1). 
Figura 1. Representação gráfica das regressões polinomiais para peso final, ganho em peso, taxa de crescimento especifico, taxa de eficiência proteica e conversão alimentar aparente de alevinos de tilápia do Nilo alimentados com dietas contendo proteína hidrolisada de frango.
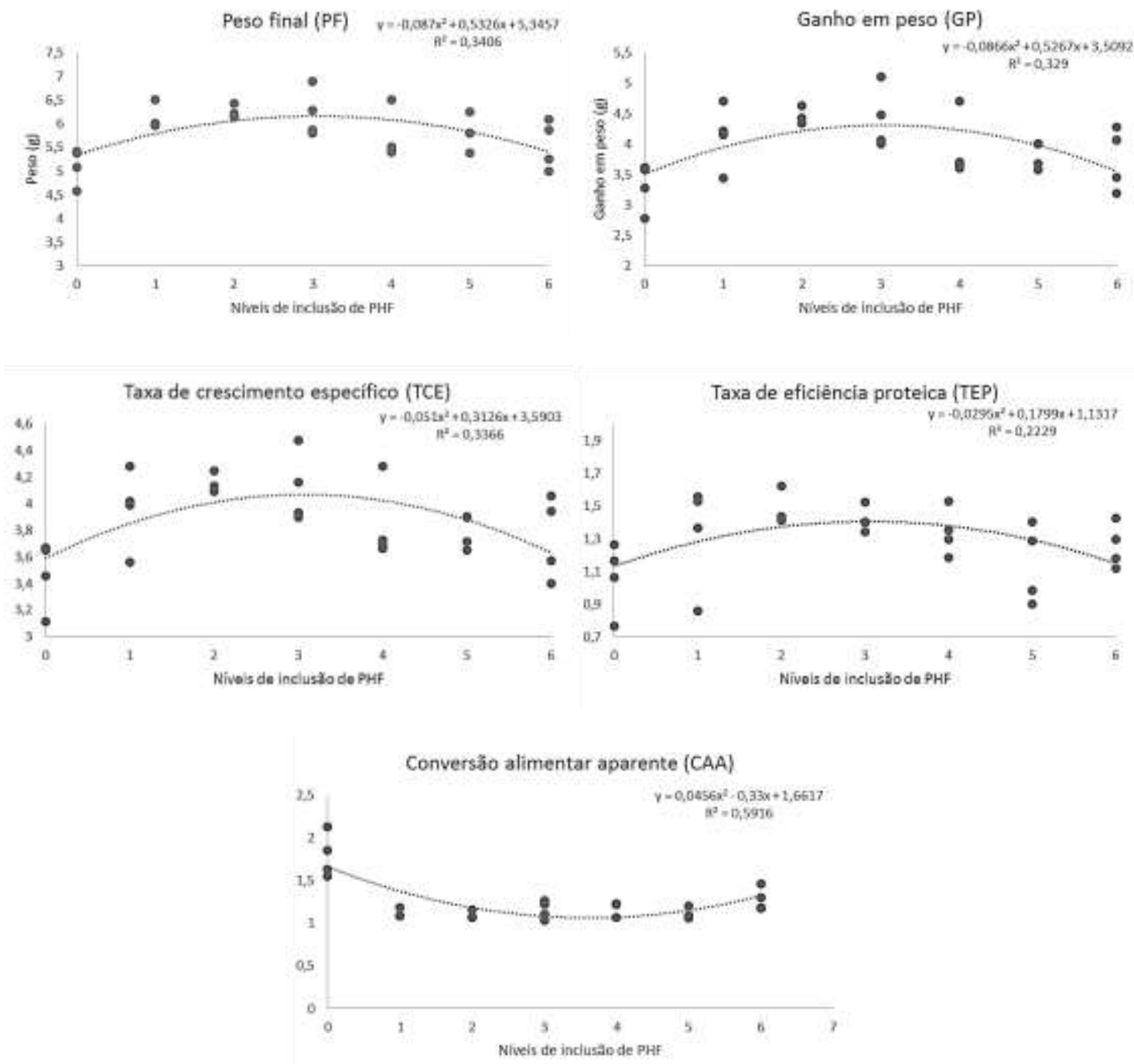

Fonte: Autores.

Salienta-se que a ração com 3\% de inclusão de PHF proporcionou 33\% de ganho em peso comparada a ração controle melhorando em 55\% a conversão alimentar nesta fase de criação. Sobretudo, os melhores resultados produtivos foram observados para a inclusão de cerca de 3\% de PHF, e estão na faixa do que se observa na literatura, onde os melhores resultados são observados com níveis de inclusão de proteínas hidrolisadas até 10\%. Zheng et al. (2011), observaram que linguado alimentado com 3,7\% de hidrolisado proteico apresentou melhor crescimento e eficiência proteica. Silva et al. (2017) observaram que pós-larvas de tilápia do Nilo alimentadas com 4,75\% de hidrolisado proteico de resíduo de pescado apresentaram melhor peso final, ganho em peso e taxa de crescimento específico.

Isto pode ser explicado devido o processo de hidrólise proporcionar maior e melhor digestibilidade dos nutrientes, onde a quebra das ligações peptídicas resulta em peptídeos de vários tamanhos e aminoácidos livres (Martone et al, 2005; Nilsang et al, 2005). Segundo Hevroy et al., (2005) essas características dos hidrolisados proteicos resultam em uma maior retenção de proteína e energia no organismo do animal, consequentemente, maiores índices nas variáveis de crescimento, como o demonstrado no presente estudo. 
Ainda sobre as características do ingrediente, o processo de hidrólise ao alterar a estrutura da proteína pode disponibilizar grupos funcionais, conferindo ao ingrediente propriedades como ação antioxidante e capacidade imunoestimulante, tornando-o um nutracêutico (Raghavan \& Kristinsson, 2008; Memarpoor-Yazdi et al, 2012; Mansour et al, 2014). Desta forma, a partir desses grupos funcionais, sugere-se uma ação promotora de crescimento do ingrediente aos animais, melhorando os índices zootécnicos dos peixes.

Além disso, Portz e Furuya (2012) ressaltam que a inclusão deve ser criteriosamente ponderada, pois o excesso de proteína e aminoácidos pode causar toxicidade, antagonismo, afetar o transporte de nutrientes dentre outros aspectos que comprometem a performance produtiva. Essa premissa também pode explicar o decréscimo dos parâmetros produtivos a medida de que se aumentou o nível da inclusão ótima, expressa pela regressão polinomial. Nesse mesmo sentido, Cahu et al. (2004) observaram que o excesso de aminoácidos livres no trato digestivo compromete a excreção de enzimas digestivas, fazendo com que estes nutrientes não sejam absorvidos, por causar toxicidade, afetar o transporte de nutrientes dentre outros aspectos.

Por outro lado, é possível que maiores quantidades de proteína na dieta não sejam destinadas para a retenção muscular e sim para a formação de energia. Tal fato é constatado por Hevroy et al., (2005), que relacionam menores índices de crescimento do salmão do atlântico aos maiores níveis de inclusão de proteína hidrolisada na deita, atribuindo isso a uma absorção assincrônica de aminoácidos essenciais comparado aos não essenciais, sendo que eles não podem ser armazenados, resultando na oxidação dos mesmos, portanto, diminuindo o anabolismo do animal.

Vale ressaltar as informações da FAO (2020), afirmando que nos próximos anos a qualidade e quantidade da farinha de peixe não atenderá os requisitos básicos para a formulação de dietas para a aquicultura. Sendo assim, o PHF se torna uma alternativa de ingrediente, tanto do ponto de vista qualitativo quanto no quantitativo, além de contribuir para uma aquicultura mais sustentável, dando destino mais nobre para coprodutos de frigoríficos, bem como diminuindo o uso de farinhas de peixe oriundas do extrativismo.

Não foram observadas diferenças $(\mathrm{p}>0,05)$ nas análises morfométricas do músculo, fígado e intestino dos animais (Tabela 3). Embora a avaliação de crescimento muscular tenha demonstrado um padrão de mosaico, com fibras musculares distribuídas em todos os tamanhos de classe, a maior concentração para fibras encontradas neste estudo são até de 50 $\mu$ m, o que evidencia que nesta fase de desenvolvimento (alevinos) o principal tipo de crescimento é por hiperplasia, ou seja, recrutamento de novas fibras musculares (Almeida et al., 2010). 
Tabela 3. Valores médios de alterações fisiológicas no músculo, fígado e intestino de alevinos de tilápia do Nilo alimentadas com rações contendo níveis de inclusão de proteína hidrolisada de frango.

\begin{tabular}{|c|c|c|c|c|c|c|c|c|}
\hline \multirow{2}{*}{ Variáveis } & \multicolumn{7}{|c|}{ Níveis de inclusão de PHF (\%) } & \multirow{2}{*}{$\begin{array}{c}\text { Valor de } \\
p\end{array}$} \\
\hline & $\mathbf{0}$ & 1 & 2 & 3 & 4 & 5 & 6 & \\
\hline \multicolumn{9}{|l|}{ Músculo $^{I}$} \\
\hline$<20$ & 19,12 & 19,37 & 21,87 & 23,44 & 22,25 & 18,01 & 19,44 & 0,3908 \\
\hline $20-50$ & 77,80 & 76,07 & 75,22 & 72,54 & 74,22 & 78,49 & 75,94 & 0,2532 \\
\hline$>50$ & 3,08 & 4,56 & 2,91 & 4,02 & 3,53 & 3,50 & 4,62 & 0,0752 \\
\hline \multicolumn{9}{|l|}{ Fígado $^{2}$} \\
\hline NH & $\begin{array}{c}232,00 \pm \\
22,14 \\
\end{array}$ & $\begin{array}{c}261,33 \pm \\
28,44 \\
\end{array}$ & $\begin{array}{c}231,44 \pm \\
24,73 \\
\end{array}$ & $\begin{array}{c}241,82 \pm \\
19,97 \\
\end{array}$ & $\begin{array}{c}237,70 \pm \\
22,15 \\
\end{array}$ & $\begin{array}{c}245,81 \pm \\
25,87 \\
\end{array}$ & $\begin{array}{c}229,44 \pm \\
24,02 \\
\end{array}$ & 0,1221 \\
\hline \multicolumn{9}{|l|}{ Intestino $^{3}$} \\
\hline $\mathrm{AV}(\mu \mathrm{m})$ & $\begin{array}{c}179,39 \pm \\
51,70\end{array}$ & $\begin{array}{c}182,68 \pm \\
57,81\end{array}$ & $\begin{array}{c}185,92 \pm \\
66,02\end{array}$ & $\begin{array}{c}190,77 \pm \\
58,93\end{array}$ & $\begin{array}{c}186,22 \pm \\
60,92\end{array}$ & $\begin{array}{c}175,11 \pm \\
57,72\end{array}$ & $\begin{array}{c}164,12 \pm \\
51,24\end{array}$ & 0,0721 \\
\hline $\mathrm{EE}(\mu \mathrm{m})$ & $\begin{array}{c}29,18 \pm \\
5,62\end{array}$ & $\begin{array}{c}29,96 \pm \\
8,24\end{array}$ & $\begin{array}{c}28,91 \pm \\
6,53\end{array}$ & $\begin{array}{c}31,26 \pm \\
7,32\end{array}$ & $\begin{array}{c}31,71 \pm \\
7,11\end{array}$ & $\begin{array}{c}29,32 \pm \\
6,92\end{array}$ & $\begin{array}{c}30,11 \pm \\
6,04\end{array}$ & 0,1023 \\
\hline
\end{tabular}

${ }^{1}$ Valores expressos em: média da distribuição de frequência em porcentagem nas classes de tamanho i) menor que $20 \mu \mathrm{m}$, ii) de 20 a $50 \mu \mathrm{m}$ e iii) maiores que $50 \mu \mathrm{m} .{ }^{2}$ Valores expressos em: média \pm desvio padrão no número total de hepatócitos $(\mathrm{NH}) .{ }^{3}$ Valores expressos em: média \pm desvio padrão da morfometria da altura do vilo (AV), espessura do epitélio (EE). Fonte: Autores.

Esse padrão de crescimento também foi verificado por Yamashiroet al. (2010), nas fases iniciais de desenvolvimento da tilápia do Nilo. A partir disto, é possível afirmar que o padrão de crescimento por hiperplasia é observado em tilápias de 0,70 gramas (Yamashiroet al. 2010) até o peso de 6,26 gramas, como demonstrado no presente estudo.

Desse modo, visando a produção cárnea na aquicultura, o processo de crescimento por hiperplasia é fundamental para o desempenho zootécnico dos animais, bem como o sucesso da produção (Rowlerson \& Veggetti, 2001).

Consequentemente, nenhuma fibra com diâmetro maior que $50 \mu \mathrm{m}$ foi observada. Como o relatado por Almeida et al.

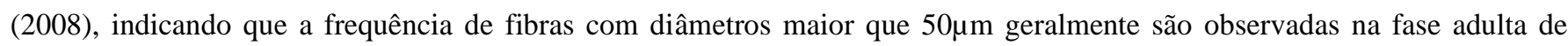
peixes teleósteos, indicando um crescimento caracterizado por hipertrofia.

O fígado é considerado um órgão indicador do estado nutricional dos animais, sendo assim, através de sua avaliação é possível indicar algum tipo de toxicidade e/ou alteração devido a ingestão de alimentos alternativos (Caballero et al., 1999). Portanto, na ocorrência de disfunções nutricionais, é possível visualizar alterações histológicas no tecido do órgão (Raskovic et al., 2011).

Embora o número total de hepatócitos não tenha diferido entre os tratamentos avaliados, o elevado valor observado neste estudo para este parâmetro denota que este alimento não causou prejuízos metabólicos aos alevinos de tilápia, visto que estas estruturas podem ser consideradas os primeiros alvos da toxicidade de uma substância, sendo o elevado valor observado uma prerrogativa de sua eficiente absorção (Zelikoff, 1998).

Ostaszewska et al. (2005), frisam que a qualidade dos alimentos está diretamente relacionada a absorção e digestão de seus nutrientes pelos peixes, sendo a integridade do fígado um dos principais meios para a avaliação da condição do animal e, consequentemente, a qualidade do ingrediente. 
Quanto a morfologia intestinal, este órgão, assim como o fígado, pode ser um indicador de disfunções nutricionais, bem como qualidade da dieta consumida (Raskovic et al., 2011). O intestino participa diretamente na digestão e absorção de nutrientes, portanto, sua morfologia está relacionada a capacidade e eficiência da absorção dos nutrientes (Zhu et al., 2012). No entanto, o presente estudo não indica qualquer alteração no órgão, visto a similaridade com a morfologia intestinal dos animais que não consumiram a dieta contendo PHF com os que a consumiram.

Portanto, é notória a qualidade nutricional do PHF, o ingrediente não causou nenhuma alteração em órgãos indicadores como fígado e intestino, bem como manteve o padrão de crescimento muscular, com relação a dieta sem a inclusão do hidrolisado, atribuindo isto ao valor nutricional do ingrediente bem como a viabilidade de sua inclusão em dietas balanceadas para as fases iniciais da tilápia do Nilo.

\section{Conclusão}

A inclusão da proteína hidrolisada de frango nas dietas melhorou os aspectos produtivos de alevinos de tilápia do Nilo em relação à dieta contendo farinha de peixe em substituição total à proteína hidrolisada de frango. Assim, para melhor expressão da performance produtiva recomenda-se a inclusão de 3\% do referido produto nesta fase de criação.

\section{Agradecimentos}

À Brasil Foods S/A Company (BRF Ingredients) por fornecer a proteína hidrolisada de frango e pelo suporte técnico.

\section{Referências}

Almeida, F. L. A., Pessotti, N. S., Pinhal, D., Padovani, C. R., Leitão, N. J., Carvalho, R. F., Martins, C., Portella, M. C., \& Dal Pai-Silva, M. (2010). Quantitative expression of myogenic regulatory factors MyoD and myogenin in pacu (Piaractus mesopotamicus) skeletal muscle during growth. Micron Oxford: Copyright Elservier Ltd, 41 (8), 997-1004.

Almeida, F. L. A., Carvalho, R. F., Pinhal, D., Padovani, C. R., Martins, C., \& Dal Pai-Silva, M. (2008). Differential expression of myogenic regulatory fator MyoD in pacu skeletal muscle (Piaractus mesopotamicus Holmberg 1887: Serrasalminae, Characidae, Teleostei) during juvenile and adult growth phases. Micron Oxford: Pergamon Elservier B.V. Ltd, 39 (8), 1306-1311.

Alves, D. R. S., Oliveira, S. R., Luczinski, T. G., Paulo, I. G. P., Boscolo, W. R., Bittencourt, F., \& Signor, A. (2019). Palatability of protein hydrolysates from industrial byproducts for nile tilapia juveniles. Animals. 9, 311-322.

Arredondo-Figueroa, J. L., Ponce-Palafox, J. T., Shirai-Matsumoto, K., Pérez-Zavaleta, A., Barriga-Sosa, I., De Los, A., \& Luna, A. R. (2013). Effects of including shrimp protein hydrolysate in practical diets on the growth and survival of redclaw crayfish hatchlings Cherax quadricarinatus (Von Martens, 1868). Aquaculture Research, 44 (6), 966-973.

Brito, J. M., Pontes, T. C., Tsujii, K. M., Araújo, F. E., \& Ricther, B. L. (2017). Automação na tilapicultura: revisão de literatura Desempenho, piscicultura, tecnologia, tilápias. Nutritime, 14 (3), 5053-5062.

Caballero, M. J, López-Calero, G., Socorro, J., Roob, F. J., Izquierdo, M. .S, \& Férnandezc, A. J. (1999). Combined effect of lipid level and fish meal quality on liver histology of gilthead seabream (Sparus aurata). Aquaculture, 179 (1-4), 277-290.

Cahu, C. L., Zambonino-Infante, J. L., \& Quazuguel, P. (2004). Protein hydrolysate vs. Fish mael in compound diets for 10-day old sea bass Dicentrarchus labrax larvae. Aquaculture, 171 (1-2), 109-119.

Dieterich, F., Boscolo, W. R., Pacheco, M. T. B., Silva, V. S. N., Gonçalves, G. S., \& Vidotti, R. M. (2014). Development and Characterization of Protein Hydrolysates Originated from Animal Agro Industrial Byproducts. Journal of Dairy, Veterinary \& Animal Research, 1 (2), 1-7.

FAO - Food and Agriculture Organization of the United Nations. (2020). The State of World Fisheries and Aquaculture. 244.

Fracalossi, D. M., Rodrigues, A. P. O., Silva, T. S. C., \& Cyrino, J. E. P. (2012). Técnicas experimentais em nutrição de peixes. In: FRACALOSSI, D. M., CYRINO, J. E. P. (Ed.). Nutriaqua: nutrição e alimentação de espécies de interesse para aquicultura brasileira. Florianópolis: Sociedade Brasileira de Aquicultura e Biologia Aquática, 2012. p.37-64.

Hevroy, E. M., Espe, M., Waagb, O. R., Sandnes, K., Ruud, M., \& Hemre, G. (2005). Nutrient utilization in Atlantic salmon (Salmo salar L.) fed increased levels of fish protein hydrolysate during a period of fast growth. Aquaculture Nutrition, 11 (4), 301-313.

Mansour, S. C., Pena, O. M., \& Hancock, R. E. (2014). Host defense peptides: Front-line immunomodulators. Trends in Immunology. 35 (9), $443-450$.

Memarpoor-Yazdi, M., e Asoodeh, A., \& Chamani, J. (2012). A novel antioxidant and antimicrobial peptide from hen egg white lysozyme hydrolysates. Journal of Functional Foods, 4 (1), 278-286. 
Mullen, A. M., Álvarez, C., Zeugolis, D. I., Henchion, M., O'Neill, E., \& Drummond, L. (2017) Alternative uses for co-products: Harnessing the potential of valuable compounds from meat processing chains. Meat Science, 132, 90-98.

National Research Council (NRC). (2011). Nutrient requirements of fish and shrimp. The national academies press, 379.

Nilsang, S., Lertsiri, S., Suphantharika, M., \& Assavaning, A. (2005). Optimization of Enzymatic Hydrolysys of Fish Soluble Concentrate by Commercial Proteases. Journal of Food Engineering, 70 (4), 571- 578.

Okamura, D., Araújo, F. G., Rosa, P. V., Freitas, R. T. F., Murgas, L. D. S., \& Cesar, M. P. (2010). Influência da concentração de benzocaína e do comprimento dos peixes na anestesia e na recuperação de tilápias-do-Nilo. Revista Brasileira de Zootecnia, 39 (5), $971-976$.

Ostaszewska, T., Dabrowski, K., Czuminska, K., Olech, W., \& Olejniczak, M. (2005). Rearing of pikeperch larvae using formulated diets-first success with starter feeds. Aquac. Res, 36 (12), 1167-1176.

Portz, L., \& Furuya, W. M. Energia, proteína e aminoácidos. In: FRACALOSSI, D. M., CYRINO, J.E.P. (Ed.). (2012). Nutriaqua: nutrição e alimentação de espécies de interesse para aquicultura brasileira. Florianópolis: Sociedade Brasileira de Aquicultura e Biologia Aquática, 65-77.

Raghavan, S., \& Kristinsson, H. G. (2008). Antioxidative efficacy of alkali-treated tilápia protein hydrolysates: a comparative study of five enzymes. Journal of Agricultural and Food Chemistry, 56 (4), 1434-1441.

Rašković, B. S., Stanković, M. B., Marković, Z. Z., \& Poleksić, V. D. (2011). Histological methods in the assessment of different feed effects on liver and intestine of fish. Journal of Agricultural Sciences, 56 (1), 87-100.

Rowlerson, A., \& Veggetti, A. (2001). Cellular mechanisms of post-embryonic muscle growth in aquaculture species. In: Johnston, I.A. (Ed.), Muscle Development and Growth. Academic Press, 103-140.

Sary, C., Paris, L. D., Bernardi, D. M., Lewandowski, V., Signor, A., \& Boscolo, W. R. (2017). Tilapia by-product hydrolysate powder in diets for Nile tilapia larvae. Acta Scientiarum - Animal Sciences, 39 (1), 1-6.

Silva, T. C., Rocha, J. D. M., Moreira, P., Signor, A., \& Boscolo, W. R. (2017). Fish protein hydrolysate in diets for Nile tilapia post-larvae. Pesquisa Agropecuária Brasileira, 52 (7), 485-492.

Valente, L. M. P., Rocha, E., Gomes, E. F. S., Silva, M. W., Oliveira, M. H., Monteiro, R. A. F., \& Fauconneau, B. (1999). Growth dynamics of white and red muscle fibres in fastand slow-growing strains of rainbow trout. Journal of Fish Biology, 55 (4), 675- 691.

Yamashiro, D., Neu, D. H., Moro, E. B., Feiden, A., Signor, A., Boscolo, W. R., \& Bittencourt, F. (2016). Performance and muscular development of nile tilapia larvae (Oreochromis niloticus) fed increasing concentrations of phenylalanine. Agricultural Sciences, 7 (12), $900-910$.

Zelikoff, J. T. (1998). Biomarkers of immunotoxicity in fish and other non-mammalian sentinel species: predictive value for mammals? Toxicology, 129 (1), 63-71.

Zheng, K., Liang, M., Yao, H., Wang, J., \& Chang, Q. (2012). Effect of dietary fish protein hydrolysate on growth, feed utilization and IGF-I levels of Japanese flounder (Paralichthys olivaceus). Aquaculture Nutrition. 18, 297-303.

Zhu, H., Liu, H., Yan, J., Wang, R., \& Liu, L. (2012) Effect of yeast polysaccharide on some hematologic parameter and gut morphology in channel catfish (Ictalurus punctatus). Fish Physiology and Biochemistry, 38 (5). 